\title{
Composição bromatológica e cinética ruminal da fibra em detergente neutro de silagens de milho e sorgo
}

\section{Chemical composition and ruminal kinetic of neutral detergent fiber of corn and sorghum silages}

\author{
Elzânia Sales Pereira ${ }^{1 *}$; Alex Martins Varela de Arruda²; Ivone Yurika Mizubuti³; \\ Fernanda Barros Moreira ${ }^{4}$; Maria Andréia Cavalcante ${ }^{5}$; \\ Sonia Maria Pinheiro de Oliveira ${ }^{1}$; Arturo Bernardo Selaive Villarroel ${ }^{1}$
}

\begin{abstract}
Resumo
O objetivo deste trabalho foi determinar a composição bromatológica e a degradação da fibra em detergente neutro (FDN) de silagens de milho e sorgo com diferentes porcentagens de espigas e panículas, conforme os seguintes tratamentos: silagem de milho com $0 \%$ de espiga; silagem de milho com $25 \%$ de espiga; silagem de milho com 50\% de espiga; silagem de milho com 75\% de espiga; silagem de sorgo com $0 \%$ de panícula; silagem de sorgo com $30 \%$ de panícula; silagem de sorgo com $60 \%$ de panícula ; silagem de sorgo com $90 \%$ de panícula. O efeito dos tratamentos sobre a degradação in situ da fibra em detergente neutro foi avaliado pela técnica de sacos de náilon, usando quatro novilhos machos mestiços HolandêsZebu fistulados no rúmen. Os teores de matéria seca (MS) da silagem de sorgo aumentaram progressivamente com a crescente adição de panícula de 0,30,60 e 90\%, apresentando teores de 18,37, $35,20,42,80$ e $59,85 \%$, respectivamente. Comportamento semelhante foi observado com as silagens de milho com valores de 19,36;24,48; 30,96 e 38,48 \% de MS para os tratamentos com adição de $0 \%, 25 \%$, $50 \%$ e $75 \%$ de espiga, respectivamente. Os maiores teores de proteína bruta (PB) da silagem de sorgo foram alcançados nos tratamentos com 60\% (9,39\%) e 90\% (9,93\%) de panícula. Os valores de FDN nas silagens de sorgo e milho decresceram à medida que aumentou as porcentagens de panículas e espigas. As estimativas de degradação efetiva, considerando a taxa de passagem de $5 \% \mathrm{~h}$ para FDN das silagens de milho, foram: 60,28 ( $0 \%$ de espiga); 58,18 (25\% de espiga); 55,30 (50\% de espiga); $54,00 \%$ (75\% de espiga) e para as silagens de sorgo: 58,22 (0\% de panícula); 50,01 (30\% de adição de panícula); 51,51 (60\% de panícula) e 45,25\% (90\% de panícula). A utilização de $90 \%$ de panícula e $75 \%$ de espiga promoveu menor degradação efetiva da FDN das silagens de sorgo e milho, respectivamente.
\end{abstract}

Palavras-chave: Avaliação de alimentos, nutrição, ruminantes

\begin{abstract}
The aim of this work was to evaluate the chemical composition and neutral detergent fiber (NDF) degradation of corn and sorghum silages with different percentages of corn cob and panicles, as the following treatments: corn silage with $0 \%$ of corn cob; corn silage with $25 \%$ of corn cob; corn silage with $50 \%$ of corn cob; corn silage with $75 \%$ of corn cob; sorghum silage with $0 \%$ of panicle; sorghum silage

1 Universidade Federal do Ceará (UFC), Depto. de Zootecnia, Fortaleza-CE, elzania@ hotmail.com.

2 Universidade federal Rural do Semi Árido (UFERSA), Depto de Zootecnia, Mossoró, RN.

3 Universidade estadual de Londrina (UEL), Depto. de Zootecnia, Londrina-PR. Pesquisadora do CNPq. E-mail: mizubuti@uel.br.

4 Bolsista PRODOC. UEL, Depto. de Zootecnia, Londrina, PR.

5 Doutora em Zootecnia, bolsista DCR- UFC.
\end{abstract}

* Autor para correspondência

Recebido para publicação 11/10/06 Aprovado em 24/04/07 
with $30 \%$ of panicle; sorghum silage with $60 \%$ of panicle; sorghum silage with $90 \%$ of panicle. The treatment effect on the NDF in situ degradation was evaluated by the nylon bag technique, using four Holandês-Zebu crossbreed steers, fitted with a ruminal cannula. Dry matter (DM) content of the sorghum silage increased progressively with to addition of $0,30,60$ and $90 \%$ of panicles, presenting 18.37, 35.20, 42.80 and $59.85 \%$ of DM, respectively. Similar behavior was observed with the corn silages with values of $19.36 ; 24.48 ; 30.96$ and $38.48 \%$ of DM for treatments with addition of $0,25,50$ and $75 \%$ of corn cob, respectively. The highest content of crude protein $(\mathrm{CP})$ of the sorghum silage were reached in the treatments with $60 \%(9,39 \%)$ and $90 \%$ (9,93\%) of panicles. The NDF values of sorghum and corn silages decreased with the increase of panicle and corn cob in the sorghum and corn silages, respectively. The estimated NDF effective degradability, considering a passage rate of $5 \% / \mathrm{h}$, of the corn silages were $60.28(0 \%$ of corn cob addition); 58.18 ( $25 \%$ of corn cob addition); 55.30 (50\% of corn cob addition); 54.00 ( $75 \%$ of corn cob addition) $\%$ and for the sorghum silages, 58.22 ( $0 \%$ of panicle addition); 50.01 (30\% of panicle addition); 51.51 (60\% of panicle addition) and 45.25 (90\% of panicle addition) $\%$. The use of $90 \%$ of panicle and $75 \%$ of corn cob promoted lowest NDF degradation of sorghum and corn silages, respectively.

Key words: Feed evaluation, nutrition, ruminants

\section{Introdução}

Para os herbívoros ruminantes, os carboidratos são as principais fontes de energia, tanto diretamente, através da absorção de seus monômeros pelo trato digestório, como indiretamente, pela sua conversão em ácidos graxos voláteis através da ação fermentativa de microrganismos, os quais suportam a síntese de proteína microbiana no rúmen-retículo, representando a principal fonte de aminoácidos disponíveis nos intestinos desses animais (VAN SOEST, 1994).

Nos sistemas usuais de produção, os ruminantes obtêm a maioria dos nutrientes a partir de volumosos, porém o nível de produção desejado nem sempre é conseguido. Daí a necessidade de melhor entendimento dos mecanismos que governam a digestão ruminal dos nutrientes consumidos. $\mathrm{O}$ conhecimento atual dos padrões cinéticos dos nutrientes no rúmen, de acordo com Mertens (1993), se deu em função do desdobramento conceitual da celulose, no início da década de 70. A quantidade de alimento que desaparece do rúmen é resultado direto da competição entre as taxas de degradação e de passagem (VAN SOEST, 1994). A manipulação dessas taxas pode culminar em maior ou menor escape de determinado nutriente e na maximização do crescimento microbiano, o que resulta em diferentes formas de utilização de energia e do nitrogênio contidos na dieta (RUSSELL et al., 1992). As técnicas de avaliação dos parâmetros cinéticos da degradação ruminal dos alimentos compreendem estudos sobre o desaparecimento da massa de amostra incubada no ecossistema ruminal permitindo conhecer a adequação nitrogenada no rúmen e nos intestinos. A técnica in situ permite o contato do alimento teste com o ambiente ruminal, embora o alimento não esteja sujeito a todos os eventos digestivos, como mastigação, ruminação e passagem (NOCEK, 1988).

Diante disso, o presente estudo foi desenvolvido para determinar a composição bromatológica de silagens de milho e sorgo com diferentes níveis de espigas e panículas, respectivamente, e a degradação ruminal da fibra em detergente neutro utilizando novilhos mestiços Holandês- Zebu.

\section{Material e Métodos}

O milho e sorgo utilizados para a produção das silagens experimentais foram obtidos no Campo experimental da Universidade Federal de Viçosa, sendo cortados quando apresentaram ponto ideal para ensilagem, e ensilados em silos experimentais adaptados com válvulas para escape de gases, perfazendo os seguintes tratamentos experimentais: silagem de milho com $0 \%$ de espiga; silagem de milho com $25 \%$ de espiga; silagem de milho com $50 \%$ de espiga; silagem de milho com $75 \%$ de espiga; silagem de sorgo com $0 \%$ de panícula; silagem de sorgo com $30 \%$ de panícula; silagem de sorgo com $60 \%$ de 
panícula; silagem de sorgo com $90 \%$ de panícula. Para determinação da composição químicobromatológica e da cinética ruminal da fibra em detergente neutro utilizou-se o Laboratório de Nutrição Animal da Universidade Estadual do Oeste do Paraná, utilizando-se quatro machos mestiços Holandês- Zebu, fistulados no rúmen e pesando em média $380 \mathrm{~kg}$ de peso vivo, os quais foram alimentados com silagem de sorgo e ração concentrada em uma proporção volumoso: concentrado de 60:40. As silagens foram moídas em moinho tipo faca com peneira de granulometria de 5 $\mathrm{mm}$. As determinações dos teores de matéria seca (MS), matéria mineral (MM), matéria orgânica (MO), proteína bruta $(\mathrm{PB})$ e extrato etéreo (EE) foram realizadas conforme os procedimentos padrões (ASSOCIATION OF OFFICIAL ANALYTICAL CHEMISTS, 1990). Fibra em detergente neutro (FDN), e ácido (FDA) foram determinados conforme Van Soest, Robertson e Lewis (1991) e proteína insolúvel em detergente ácido (PIDA) e neutro (PIDN) conforme Licitra, Hernandez e Van Soest (1996). Os teores de carboidratos totais (CT) e carboidratos não estruturais (CNE), foram obtidos conforme recomendações de Sniffen et al. (1992).

As amostras dos diferentes tratamentos foram colocadas em sacos de náilon medindo $7 \times 5 \mathrm{~cm}$, com 50mm de abertura de malha, os quais foram submetidas á secagem em estufa com ventilação forçada a $55^{\circ} \mathrm{C}$ por 48 horas; em seguida, foram resfriados em dessecador e pesados. As amostras das silagens foram colocadas nos sacos de náilon, em quantidades aproximadas de $1 \mathrm{~g}$ de MS por saco e incubados na parte ventral do rúmen de cada novilho nos tempos de: 6, 48, 96 e 144 horas. Após o período de incubação os sacos foram lavados em água corrente e em seguida, submetidos à secagem em estufa por um período de 72 horas. Finalmente foram colocados em dessecador até esfriarem e pesados novamente. Os sacos referentes ao tempo zero (utilizados para se determinar a fração prontamente solúvel) foram lavados em água corrente e posteriormente receberam os mesmos procedimentos destinados aos demais tempos. Os resíduos remanescentes nos sacos foram analisados quanto aos teores de fibra em detergente neutro (VAN SOEST; ROBERTSON; LEWIS, 1991). Os procedimentos para a determinação da degradação da FDN foram obtidos por diferença de peso encontrado para cada componente entre as pesagens, antes e após a incubação ruminal e expressos em porcentagem.

Os dados obtidos nos diferentes tempos de incubação (variável independente) foram ajustados para uma regressão não linear pelo método de GaussNewton (NETER; WASSERMAN; KUTNER, 1985), contido no pacote computacional SAEG Sistema de Análises Estatísticas e Genéticas (UNIVERSIDADE FEDERAL DE VIÇOSA, 1998), conforme a equação proposta por Orskov e McDonald (1979):

$$
\mathrm{Y}=\mathrm{a}+\mathrm{b}\left(1-\mathrm{e}^{-\mathrm{c} t}\right), \text { onde: }
$$

$\mathrm{Y}=$ degradação acumulada do componente nutritivo analisado, após um tempo t;

$\mathrm{a}=$ intercepto da curva de degradação quando t é igual a 0 , que corresponde à fração solúvel em água do componente nutritivo analisado;

$\mathrm{b}=$ é o potencial de degradação da fração insolúvel em água do componente nutritivo analisado;

$a+b=$ degradação potencial do componente nutritivo analisado quando o tempo não é um fator limitante; $c=$ taxa de degradação por ação fermentativa de b; $\mathrm{t}=$ tempo de incubação.

Uma vez calculados os coeficientes a, b, c, estes foram aplicados à equação proposta por Orskov e McDonald (1979).

$$
P=a+\frac{b \times c}{c+k},
$$

onde: $\mathrm{P}=$ degradação ruminal efetiva do componente nutritivo analisado; $\mathrm{k}=$ taxa de passagem do alimento. Assumiu-se uma taxa de passagem da digesta para o duodeno de $5 \%$ por hora, $\mathrm{k}=0,05 \%$ (ORSKOV; McDONALD, 1979). 


\section{Resultados e Discussão}

Os resultados referentes à composição bromatológica das silagens de milho e sorgo estão expressos na Tabela 1. As silagens apresentaram valores diferenciados sob o aspecto dinâmico obtidos através do fracionamento.

Observa-se pela Tabela 1 que as silagens de sorgo apresentaram aumento progressivo nos teores de matéria seca (MS) a partir de níveis crescentes de adição de panícula; $0 \%$ (18,37\%), 30\% (35,20\%), $60 \%(42,80 \%)$ e $90 \%(59,85 \%)$. Comportamento semelhante foi observado com as silagens de milho com diferentes proporções de espiga registrando-se valores de 19,36; 24,48; 30,96 e 38,48\% de MS para os níveis de adição de $0 \%, 25 \%, 50 \%$ e $75 \%$ de espiga, respectivamente.

Os teores de MS apresentados pelas silagens sugerem que a baixa porcentagem de MS encontrada para silagem de sorgo com $0 \%$ de inclusão de panícula $(18,37 \%)$ poderia favorecer o desenvolvimento de microorganismos indesejáveis, principalmente bactérias do gênero Clostridium. O maior teor de MS é desejável, pois além de contribuir para a conservação do material ensilado inibindo o desenvolvimento de microrganismos desfavoráveis, também aumenta a concentração de nutrientes, e o consumo pelos animais (PIZARRO, 1978).

Observa-se que os maiores teores de proteína bruta (PB) da silagem de sorgo foram alcançados nos tratamentos com $60 \%(9,39 \%)$ e $90 \%(9,93 \%)$ de panícula, verificando-se a influência de panículas no acréscimo do teor de PB das silagens (Tabela 1).

A silagem de sorgo com $0 \%$ de panícula apresentou baixo teor protéico sob a forma absoluta $(3,22 \%)$, o que permite inferir, um baixo suprimento de compostos nitrogenados para microrganismos ruminais, principalmente fermentadores de carboidratos estruturais, e consequientemente, uma redução de disponibilidade protéica ao longo do trato digestório.

Pode-se afirmar que concentrados formulados com alimentos que apresentem significativos teores de nitrogênio não protéico (NNP), bem como o uso de uréia, poderiam maximizar a utilização de silagens com adição de $0 \%$ de panícula e $0 \%$ de espiga pelos animais, pelo fato dessas combinações favorecerem o crescimento de bactérias que utilizam carboidratos estruturais e carboidratos não estruturais (SNIFFEN et al., 1992).

Tabela 1. Composição bromatológica das silagens, expressa na base da matéria seca.

\begin{tabular}{ccccccccc}
\hline Itens & \multicolumn{5}{c}{ SORGO $^{\mathrm{a}}$} \\
\cline { 2 - 8 } & $0 \%$ & $30 \%$ & $60 \%$ & $90 \%$ & $0 \%$ & $25 \%$ & $50 \%$ & $75 \%$ \\
\hline $\mathrm{MS}(\%)$ & 18,37 & 35,20 & 42,80 & 59,85 & 19,36 & 24,48 & 30,96 & 38,48 \\
$\mathrm{~PB}^{1}$ & 3,22 & 8,46 & 9,39 & 9,93 & 4,89 & 5,95 & 7,06 & 7,72 \\
$\mathrm{MM}^{1}$ & 9,71 & 7,05 & 6,43 & 5,00 & 5,18 & 3,49 & 2,34 & 1,70 \\
$\mathrm{MO}^{1}$ & 90,29 & 92,95 & 93,57 & 95,00 & 94,82 & 96,51 & 97,66 & 98,30 \\
$\mathrm{EE}^{1}$ & 0,46 & 2,08 & 1,46 & 2,25 & 0,46 & 0,43 & 1,10 & 0,63 \\
$\mathrm{FDN}^{1}$ & 69,22 & 58,90 & 46,32 & 45,96 & 70,41 & 50,01 & 41,02 & 37,41 \\
$\mathrm{CHT}^{1}$ & 86,61 & 82,41 & 82,72 & 82,82 & 89,47 & 90,13 & 89,49 & 89,93 \\
$\mathrm{FND}_{\mathrm{CP}}{ }^{1}$ & 63,56 & 51,35 & 44,58 & 43,32 & 69,20 & 49,01 & 40,80 & 35,65 \\
$\mathrm{CNE}^{1}$ & 17,39 & 23,51 & 38,14 & 39,50 & 20,27 & 41,12 & 48,69 & 54,28 \\
LIG $^{2}$ & 7,25 & 6,81 & 6,30 & 4,20 & 6,38 & 5,05 & 4,80 & 2,80 \\
PIDN $^{3}$ & 2,02 & 2,24 & 5,39 & 4,48 & 14,46 & 9,90 & 6,44 & 3,92 \\
PIDA $^{3}$ & 1,91 & 3,51 & 6,52 & 6,81 & 8,75 & 2,92 & 2,76 & 1,32 \\
\hline
\end{tabular}

a - $\%$ de panículas, ${ }^{\mathrm{b}}$ - $\%$ de espigas, ${ }^{1}$ - $\%$ na MS, ${ }^{2}-\%$ na FDN, ${ }^{3}-\%$ da PB 
Os valores de FDN nas silagens de sorgo e milho decresceram à medida que aumentou as porcentagens de panículas e espigas. As silagens produzidas com adição de $75 \%$ de espiga de milho apresentaram valores de FDN de 37,41\%, que segundo Mertens (1993), estão dentro de limites máximos recomendados para animais que produzam acima de $30,0 \mathrm{~kg}$ de leite/dia, em virtude de permitir adequada fermentação no rúmen, ruminação e salivação, necessários à prevenção de distúrbios metabólicos.

As estimativas dos coeficientes $a, b, c$ da equação ajustada para a degradação da FDN encontram-se nas Tabelas 2 e 3, respectivamente, para a silagem de sorgo e silagem de milho. Verifica-se que o valor do coeficiente b para silagens de sorgo foi similar, apresentando um valor médio da ordem de $80,68 \%$.
As pequenas variações podem ser atribuídas à própria composição das silagens e as maiores diferenças, às perdas de partículas durante as lavagens dos sacos (NOCEK,1988).

Observa-se pela Tabela 2 maiores taxas de degradação (c) para silagens constituídas de $0 \%$ e $30 \%$ de panícula, o que pode ser explicado pela baixa inclusão de panícula, promovendo taxa de degradação/hora relativamente maior para a fração FDN quando comparados aos demais níveis de inclusão de panícula. No entanto, Chesson, Gordon e Lomax (1985), explicaram que dietas com conteúdo de parede celular semelhantes podem apresentar variações nas taxas de degradação (c), resultantes da preferência das bactérias ruminais por diferentes tipos de tecidos.

Tabela 2. Coeficientes de degradação a, b, c e degradação efetiva (DE) da fibra em detergente neutro (FDN) das silagens de sorgo

\begin{tabular}{llllll}
\hline Silagem de sorgo & $\mathrm{a}$ & $\mathrm{b}$ & $\mathrm{c}$ & $\mathrm{DE}$ & $\mathrm{R}^{2}$ \\
\hline 0\% panícula & - & 85,50 & 0,020 & 58,22 & 0,90 \\
30\% panícula & - & 81,47 & 0,020 & 50,01 & 0,95 \\
60\% panícula & - & 80,50 & 0,019 & 51,50 & 0,93 \\
$90 \%$ panícula & - & 75,25 & 0,017 & 45,25 & 0,91 \\
\hline
\end{tabular}

$\mathrm{a}=$ fração rapidamente solúvel; $\mathrm{b}=$ fração potencialmente degradável; $\mathrm{c}=$ taxa de degradação; $\mathrm{DE}=$ degradação efetiva; $\mathrm{R}^{2}=$ coeficiente de determinação.

Tabela 3. Coeficientes de degradação a, b, c e degradação efetiva (DE) da fibra em detergente neutro (FDN) das silagens de milho.

\begin{tabular}{llllll}
\hline Silagem de milho & $\mathrm{a}$ & $\mathrm{b}$ & $\mathrm{c}$ & $\mathrm{DE}$ & $\mathrm{R}^{2}$ \\
\hline 0\% espiga & - & 39,20 & 0,045 & 60,28 & 0,92 \\
25\% espiga & - & 37,05 & 0,041 & 58,18 & 0,92 \\
$50 \%$ espiga & - & 36,20 & 0,038 & 55,30 & 0,94 \\
$75 \%$ espiga & - & 35,18 & 0,025 & 54,00 & 0,90 \\
\hline
\end{tabular}

$\mathrm{a}=$ fração rapidamente solúvel; $\mathrm{b}=$ fração potencialmente degradável; $\mathrm{c}=$ taxa de degradação; $\mathrm{DE}=$ degradação efetiva; $\mathrm{R}^{2}=$ coeficiente de determinação.

Segundo Rooney e Plfugfelder (1986), o sorgo apresenta menor degradação, devido, principalmente, à presença de endosperma periférico, o qual é extremamente denso ao ataque microbiano. Para silagens de milho produzidas com diferentes níveis de inclusão de espiga registrou-se valor médio de $36,91 \%$ para a fração potencialmente degradável (b), sendo que silagens de milho com $50 \%$ e $75 \%$ de inclusão de espiga apresentaram, menores taxas de degradação, 0,038 e 0,025, respectivamente.

Nas Tabelas 2 e 3, são mostradas as degradações efetivas da FDN das silagens, considerando-se taxa de passagem de $5 \% / \mathrm{h}$. Os valores de degradação efetiva da FDN de silagens de sorgo com $0 \%$ de 
adição de panícula $(58,22 \%)$, é superior ao obtido por Martins et al. (1999), o qual registraram degradação efetiva para silagem de sorgo exclusiva de $46 \%$, utilizando taxa de passagem de $5 \% / \mathrm{h}$ como realizado no presente trabalho.

Para degradação da parede celular das silagens de milho foram obtidos valores comumente reportados na literatura $(56,94 \%)$, no entanto, as silagens produzidas com maiores percentuais de espigas apresentaram menores degradações efetivas quando comparadas à silagem com $0 \%$ de espiga. Tal fato pode ser explicado em virtude da natureza gelatinosa do amido oriundo dos grãos de milho no interior dos sacos, sendo um material com tendência a se aglutinar, quando úmido, ocasionando, provavelmente, menor exposição da área superficial da FDN de folha/caule do milho, impedindo as partículas de se movimentarem dentro dos sacos (COZZI; BITTANTE; POLAN, 1992).

\section{Conclusão}

A utilização de $90 \%$ de panícula e $75 \%$ de espiga promoveu menor degradação efetiva da FDN das silagens de sorgo e milho, respectivamente.

\section{Referências}

ASSOCIATION OF OFFICIAL ANALYTICAL CHEMISTS. Official methods of analysis. 15.ed. Virginia: AOAC, 1990. v.1.

CHESSON, A.; GORDON, A. H.; LOMAX, J. A. Methylation analysis of mesophyll, epirmis, and fiber cells-walls isolated from the leaves of perennial and Italian ryegrass. Carbohydrate Research, Amsterdam, v.141, p.137-147, 1985.

COZZI, G.; BITTANTE, G.; POLAN, C. E. Comparison of fibrous materials as modifiers of in situ ruminal degradation of corn gluten meal. Journal of Dairy Science, Champaign, v.6, n.4, p.1106-1113, 1992.

LICITRA, G.; HERNANDEZ, T. M.; VAN SOEST, P. J. Standardization of procedures for nitrogen fractionation of ruminant feeds. Animal Feed Science and Technology, Amsterdam, v.57, p.347-358, 1996.
MARTINS, A. S.; ZEOULA, L. M.; PRADO, I. N.; MARTINS, E. N.; LOYOLA, V. R. Degradação ruminal in situ da matéria seca e proteína bruta das silagens de milho e sorgo e de alguns alimentos concentrados. Viçosa- MG. Revista Brasileira de Zootecnia, Viçosa, v.28, n.5, p.11091117, 1999.

MERTENS, D. R. Rate and extent of digestion. Chap. II. In: FORBES, J. M.; FRANCE, J. (Eds). Quantitative aspects of ruminant digestion and metabolism. Cambridge: Commonwealth Agricultural Bureaux, Cambridge University Press, 1993. p.13-51.

NETER, J.; WASSERMAN, W.; KUTNER, M. H. Linear Statistical models: regression analysis of variance, and experimental designs. 2.ed. [Illinois]: Richard d. Irwin, 1985.

NOCEK, J. E. In situ and other methods to estimate ruminal protein and energy digestibility: a review. Journal of Dairy Science, Champaign, v.71, n.8, p.2070-2107, 1988.

ORSKOV, E. R.; McDONALD, T. The estimation of protein degradability in the rumen from incubation measurements weighted according to rate of passage. Journal Agricultural Science, Cambridge, v.92, n.2, p.499-503, 1979.

PIZARRO, E. A. Conservação de forragens. I silagem. Informe Agropecuário, Belo Horizonte, v.4, n.47, p.20-28, 1978.

ROONEY, L W.; PFLUGFELDER., R. L. Factors affecting starch digestibility with special emphasis on sorghum and corn. Journal of Animal Science, Champaign, v.63, p.1607$1623,1986$.

RUSSEL, J.B.; O'CONNOR, J. D.; FOX, D. G.; VAN SOEST, P. J.; SNIFFEN, C. J. A net carbohydrate and protein system for evaluating cattle diets: I. Ruminal fermentation. Journal of Animal Science, Champaign, v.70, n.12, p.3551-3561, 1992.

SNIFFEN, C. J.; O'CONNOR, J. D.; VAN SOEST, P. J.; FOX, D. G.; RUSSELL, J. B. A net carbohydrate and protein system for evaluating cattle diets: II. Carbohydrate and protein availability. Journal of Animal Science, Savoy, v.70, n.12, p.3562-3577, 1992.

UNIVERSIDADE FEDERAL DE VIÇOSA. Sistema de análises estatísticas e genética. Viçosa: UFV, 1998. (Apostila).

VAN SOEST, P. J.; ROBERTSON, J. B.; LEWIS, B. A. Methods for dietary fiber, neutral detergent fiber, and nonstarch polyssacharides in relation to animal nutrition. Journal of Animal Science, Champaign, v.74, n.10, p.35833597. 1991.

VAN SOEST, P. Nutritional ecology of the ruminant. Ithaca: Cornell University Press, 1994. 